\title{
INTERACTION AND INTERDETERMINATION OF COMPETITION PROCESSES AND INFORMATION ASYMMETRY ON THE REGIONAL TRADE MARKET
}

The present article is to define the "information asymmetry" term depending on the information type; to prove incapability of the existing signs of smoothing of information asymmetry effects; and to substantiate an urgent need for generation of an information and economic mechanism aimed at formation of competitive environment on the trade market on the basis of information asymmetry level management.

The recent decades proved a fundamental role of competition to play in the economic system development. Alongside with that, competitive environment on many commodity markets of the Russian Federation does not exist for a number of reasons. According to the researches, information asymmetry takes a particular place among many factors influencing competitive environment generation on modern trade markets.

The "information asymmetry" term is very widespread at present and it is used quite often. However, we have to admit that the notion itself defined by the term has not still been properly qualified. In modern economics "information asymmetry" is understood as unbalanced dist-ribution of information among market participants - the information that is essential to make a proper decision in the context of bargaining. Such a definition does not imply deep necessity in implementation of the "information asymmetry" term in business economics. In the present research work we would like, first, to demonstrate that the "information asymmetry" notion is employed in the economic analysis not randomly, it is required for deeper understanding of a trade market functioning; second, to substantiate the fact that state interference with trade market competition processes is required through application of an information and economic mechanism.

Analysis of an origin regarding "asymmetry" and "information" terms made it possible to classify information asymmetry concepts as follows (Table 1).

It is evident that any economic system functions on the basis of secondary information. Therefore, the second asymmetry type definition (ref. Table 1) is to be employed in the context of the economic analysis, and information is to be understood as the data reducing ambiguity of a certain situation for a market participant. [1] In its turn, both symmetry and asymmetry features may refer to market participant awareness. In this case secondorder information asymmetry occurs, which is to be understood as a diversity measure in terms of market participant awareness about essential data required for reasonable behavior. 
Table 1

Asymmetry concepts according to information type

\begin{tabular}{|l|l|}
\hline Asymmetry type & Type description \\
\hline 1 & 2 \\
\hline $\begin{array}{l}\text { The term, which includes unbalanced } \\
\text { distribution of information concerning } \\
\text { system elements and their movements, in } \\
\text { certain conditions and certain relations, } \\
\text { in different environmental conditions. } \\
\text { Primary information asymmetry appears } \\
\text { as a result of stable ordered motion } \\
\text { af system elements. System element } \\
\text { asymetryement is unsteady, which is why } \\
\text { asymmetric development of the system } \\
\text { itself occurs and the information related } \\
\text { to the system development process } \\
\text { is distributed. The given process is } \\
\text { independent of humans. }\end{array}$ \\
\hline $\begin{array}{l}\text { Secondary } \\
\text { information } \\
\text { asymmetry }\end{array}$ & $\begin{array}{l}\text { A measure referred to irregular } \\
\text { distribution within the system of } \\
\text { individual awareness regarding certain } \\
\text { data in terms of maximum possible } \\
\text { awareness. }\end{array}$ \\
\hline $\begin{array}{l}\text { Asymmetry be- } \\
\text { tween primary } \\
\text { and secondary } \\
\text { information }\end{array}$ & $\begin{array}{l}\text { Diversity measure in terms of } \\
\text { information produced by an individual in } \\
\text { reference to reality. }\end{array}$ \\
\hline
\end{tabular}

Information asymmetry definition introduced by the authors makes it possible to research the given category on a reasonable basis with the application of all modern mathematic tools; to develop an approach to the measure process; to determine a quantitative level of information asymmetry on the market; and to trace features of asymmetry influence on structural market changes by way of modeling.

In the context of the given paper an analysis into competition process interaction and information asymmetry interference is carried out on the basis of the regional trade market of ferroconcrete products of the Perm region as a case study. Based on the results of the survey carried out in 2007, an information network of the ferroconcrete market connecting a group of agents and securing their information interaction has been generated [2]. An analysis of such a network affords an opportunity to reveal particular segments and information interaction features in reference to market participants. Record of all the enterprises within the given information network was impossible due to their refusal to go through the questionnaire. However, the network includes all the key enterprises of the sector under investigation, which take $80 \%$ of the market total share. Therefore, the analysis results and the trends revealed can be considered as reliable. Generation of connections was accomplished on the ground of the case when enterprises considered each other as major competitors, i.e. information connections only among the main competitors have been taken into consideration.

In the context of the given information network four main competition segments can be singled out (fig.). The first segment includes competition among three major enterprises on the market: the Perm Silicate Panel Plant (1), Stroypanelkomplekt (2) and Permtranszhelezobeton (3). With three market participants having significant market shares and dominant positions, competitive pressure becomes possible to exert upon each other that can be manifested as barriers in terms of distribution of information referred to market characteristics [3]. The reason is that the information is an active component within the competition mechanism; therefore, an access to the most valuable information is either restricted or not available. So far as information acts as a competitive edge, which is not always actualized within the framework of the set rules by the market participants (opportunistic policy), the information field is distorted and information becomes asymmetric as a result. Under unfair competition along with other invariable conditions the market will be monopolized by degrees, and it will result in reduction of its efficient functioning.

The second segment includes the Ferroconcrete Integrated Plant -7 (4), the Ferroconcrete Integrated Plant - 1 (5), Stroymarket (6), the Ferroconcrete Products Plant "Stroyindustriya" (7). The third segment includes the Ferroconcrete Integrated Plant - 1 (5), Stroymarket (6) and Kras-nokamsk Ferroconcrete Integrated Plant (8). The second and the third segments are formed by the enterprises, which have great operational experience as market participants, but considerably less sales volume in comparison to the first three leaders. Market analysis for the past five years demonstrates the fact that the Ferroconcrete Integrated Plant -7 and the Ferroconcrete Integrated Plant -1 consider themselves as powerful enterprises within the given segments, and this can be proved by their relatively stable market shares and mutual identification between the Ferroconcrete Integrated Plant -1 and the Perm Silicate Panel Plant as competitors. The fourth segment includes "Uralzhelezobeton" (10), "Sentyabr" (9) and the Krasnokamsk Ferroconcrete Integrated Plant (8). Smaller segments can be traced in the market as well: the "Ferroconcrete Products Plant - Monolit" (12) - "Ellina" (11), "Tehnologiya" (14) - Zakamsk Ferroconcrete Integrated Plant (17), "Sentyabr" - "Zhelezobeton" (13), "Zhelezobeton" "Stroymarket", "Stroymarket" - "Ferroconcrete Products Plant - Monolit". Enterprises with less 


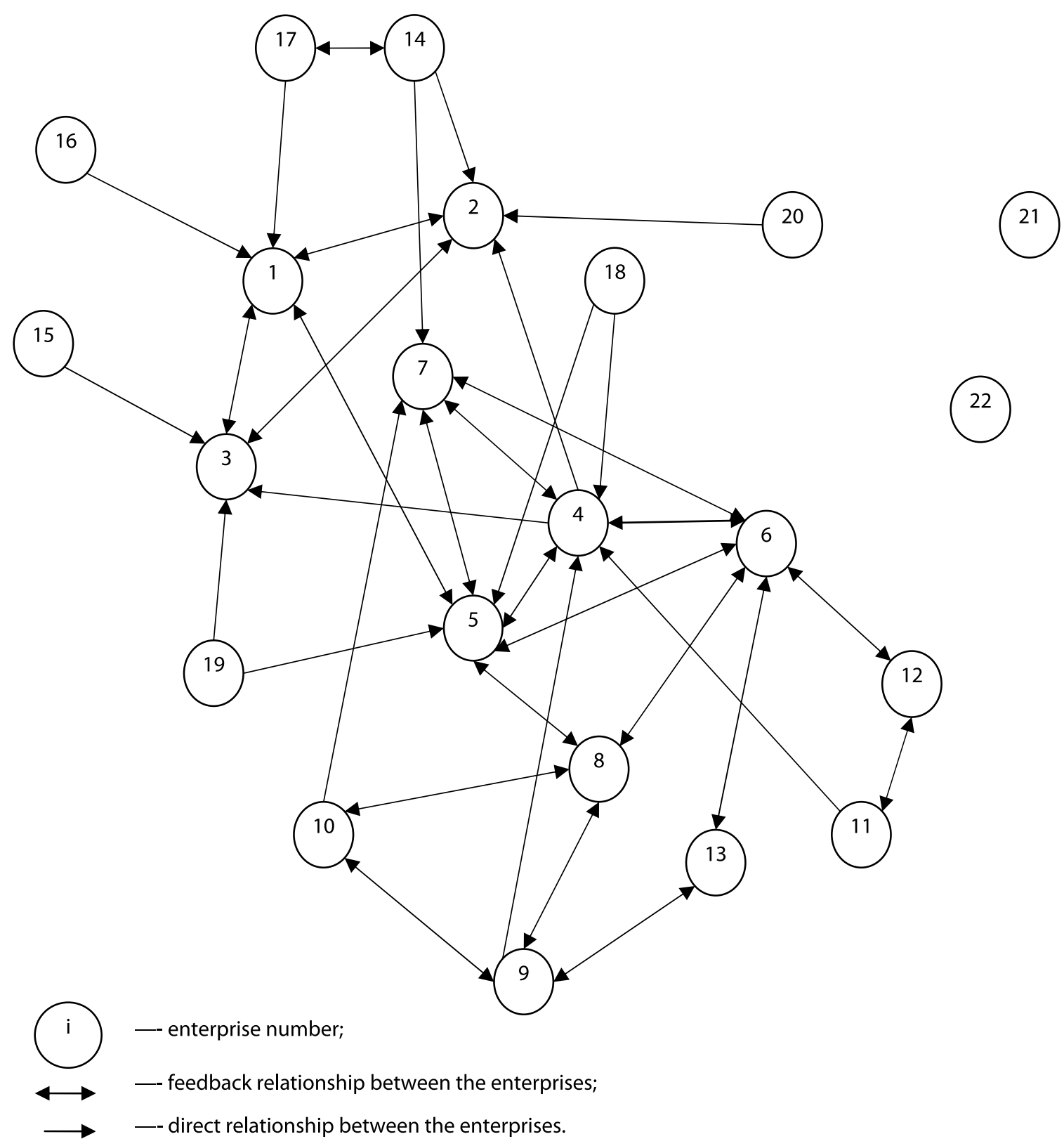

Fig. Information network referred to the ferroconcrete trade market of the Perm region

than $3 \%$ of the market share compete within the given segments. These are generally small but efficient enterprises with a sustainable market position. Relatively small size of such enterprises makes it possible to adopt a flexible market policy and to adapt to the changing market conditions as rapidly as possible. Thus, "Zhelezobeton" company totally upgraded the production line in 2006 and now it can take requirements by building companies into consideration in the process of nonstandard item production. However, the enterprises within the given segments possess much less financial resources, which is why essential information for efficient operation is available only for the large companies possessing considerable financial resources. The research results have also demonstrated the fact that several small companies are isolated and they do not take part in the competition due to the fact that large enterprises do not regard companies with the market share of less than $2 \%$ as competitors [4].

Generation of local monopolies or (and) local market segments is due to high quantity of information connections among a great amount of both customers and sellers in the context of perfect competition. Therefore, information connection quantity grows and respectively transaction costs for keeping market participants connected with each other grow as well in the process of the market participant quantity growth. The market functions under the condition of information asymmetry.

This fact can be explained as follows: within a perfect competition model each seller has $m$ 
information connections with customers and $(n-1)$ connections with other sellers; the total quantity of sellers' information connections is $n(m+(n-1))$; each customer has $\mathrm{n}$ information connections with sellers and $(m-1)$ connections with other customers and the total quantity of customer connections is $m(n+(m-1))$. Therefore, the total amount of connections in the given $\mathrm{N}$ model will be equal to [5]:

$$
\begin{gathered}
N=n(m+(n-1))+m(n+(m-1))= \\
=(n+m) 2-n-m=(n+m)(n+m-1) .
\end{gathered}
$$

According to the Federal State Statistics Service, the ferroconcrete production sellers in the Perm region amounted to 47 enterprises $(n)$ in 2007 , and the customers (building companies occupied in general construction of buildings, $m$ ) amounted to 256 enterprises. Thus, by applying formula (1) one could calculate the quantity of connections, which should have been amounted to 91506 with the symmetric information distribution. However, according to the research and the market network analysis, an actual number of information connections is much less and the information is asymmetric.

While analyzing competitive interaction between market participants on the basis of the competition form classification by V.V. Kruglov [6], we can single out two main forms established in the given market: neutrality and mild conflict. Neutrality is a form of interaction, in the context of which two market participants do not consider each other as competitors. In a mild conflict market participants compete occasionally, but such a competition does not turn into acute rivalry (antagonism) that stimulates the system to develop. In order to generate such a form of competition in the system, symmetric information exchange between the system elements is required [6]. Therefore, market participants strictly identify their principal competitors and enter into a mild conflict with them, and secondary competitors, which they do not compete with.

With competitive interaction of market participants and the market structure taken into account, an analysis of the market concentration rates has been carried out, and it has demonstrated the fact that the market had tended to be moderately concentrated from 2003 to 2007 (Table 2).

Thus, the ferroconcrete trade market of the Perm region is specified at present by lack of actual competition, presence of local monopolies and market segments, opportunities for manipulation through information asymmetry.

The recent researches demonstrate decreasing scale efficiency by most enterprises of the given market [7]; disintegration processes have been observed in the construction complex during the last decade: single subdivisions within large enterprises are separated into independent economic entities. The given trend is due to determination for improvement of functioning efficiency of an enterprise [8]. The results of the analysis carried out by the authors did not show disintegration processes on the ferroconcrete trade market of the Perm region, but a constantly growing number of market participants has been testified. On the one hand, enterprise quantity growth on the market results in gradual decrease of the concentration level. On the other hand, such reforms contribute to information connection number and transaction cost growth as an information asymmetry factor. In this case more local monopolies or competition segments will be generated on the market, and it will result in intensification of negative effects due to information asymmetry level growth.

The research carried out by the authors is indicative of the fact that a quality scale level of

Table 2

Dynamics of rates specifying monopolization extent with regard to the ferroconcrete trade market in the Perm region ${ }^{1}$

\begin{tabular}{|l|c|c|c|c|c|c|c|}
\hline \multicolumn{1}{|c|}{ Name of rates } & $\mathbf{2 0 0 3}$ & $\mathbf{2 0 0 4}$ & $\mathbf{2 0 0 5}$ & $\mathbf{2 0 0 6}$ & $\mathbf{2 0 0 7}$ & $\mathbf{2 0 0 8}$ & $\mathbf{2 0 0 9}$ \\
\hline Quantity of enterprises & 24 & 26 & 27 & 28 & 47 & 35 & 34 \\
\hline Concentration index for three enterprises, C & 0,554 & 0,524 & 0,543 & 0,479 & 0,467 & 0,588 & 0,524 \\
\hline Herfindahl-Hirschmann Index, HHI & 1388,3 & 1216,8 & 1264,1 & 1083,6 & 918,5 & 1500,9 & 1216,5 \\
\hline Entropy index & 0,098 & 0,094 & 0,093 & 0,091 & 0,060 & 0,068 & 0,078 \\
\hline Hall-Timan Index & 0,124 & 0,114 & 0,105 & 0,103 & 0,077 & 0,117 & 0,103 \\
\hline Lind Index & 9 & 2 & 18 & 12 & 4 & 9 & 9 \\
\hline Gini Index & 0,664 & 0,663 & 0,648277 & 0,652 & 0,722 & 0,75 & 0,69 \\
\hline Variation index & 19,999 & 21,756 & 22,335 & 23,364 & 40,926 & 30,76 & 29,19 \\
\hline Market share dispersion & 0,0040 & 0,0032 & 0,0033 & 0,0026 & 0,0015 & 0,0035 & 0,0028 \\
\hline Relative concentration index & 1,173 & 1,041 & 1,215 & 1,390 & - & 0,95 & 0,86 \\
\hline
\end{tabular}

${ }^{1}$ According to the Territorial Body for State Statistics in the Perm region.

* Values of the authors. 
a product on the ferroconcrete trade market is impossible to identify without advanced studies. In the context of information asymmetry between customers and sellers regarding the quality of goods, strategic behavior of sellers of low-quality goods is aimed at profit maximization. They set a price equal to that for high-quality products, since customers are unable to evaluate the quality of a product until they buy it. As a result, a single price for goods of all quality ranks is generated on the market, and it reduces intensity of non-price competition.

Due to high product differentiation according to the quality scale, the All-Union State Standards do not favor information asymmetry level reduction on the ferroconcrete trade market. They only assure the customers that the product reaches the minimal quality standard. Information asymmetry regarding the quality on the ferroconcrete trade market appears in incompatibility of quality rating in design documentation to the current situation, and it raises the risk of structural damage in the future. Furthermore, customers do not have an incentive to carry out regular laboratory examinations of articles in order to determine an actual quality level. Thus, under asymmetric information distribution regarding quality, producers of ferroconcrete items have an opportunity to sell low-quality production at the same prices as for high-quality production, which is used straight for construction.

According to the analysis, construction products are sold at levels both above and below the regulatory requirements [9].

In case of information asymmetry regarding commodity prices between sellers and buyers, strategic behavior of sellers depends not only on strategic behavior of competitors but also on the awareness of customers as to commodity prices and transaction costs for information retrieval. Strategic behavior of sellers in such a situation is directed to a step-by-step increase in commodity prices, and it affords them an opportunity to hold an annuity on information asymmetry. Thus, the questionnaire results referred to the economic entities of the ferroconcrete trade market of the Perm region demonstrate the fact that awareness of the customers regarding the ferroconcrete production prices is at different levels. As a result, differently informed customers buy the same product at different prices.

Modern economics is familiar with several mechanisms and smoothing signs referred to information asymmetry effects (price, reputation, standardization, warranty, auctions and wasteful expenditures). However, the results of the analysis have demonstrated inconsistency in smoothing information asymmetry negative effects.
Price on a market with information asymmetry does not imply quality so far as it bears unreliable information for a customer due to the associated issue of "principal-agent". The given aspect was described above in the course of the analysis of information asymmetry between sellers and customers regarding quality and prices.

Standardization and certification of products, as was described above, do not decrease an information asymmetry level either. These measures can be used for anticompetition purposes and they appear to be the barriers for competitive economic development.

Company reputation is a sign of high-quality production. However, such a sign accelerates monopolization process on the market with information asymmetry due to the fact that a customer is unable to make a reasonable decision about which seller to choose, preferring to employ services of a reliable one. In this case information asymmetry appears as a particular mechanism, which forms entry barriers along with intensification of a reputation effect.

Warranty does not signify quality on all the markets. Thus, regarding the ferroconcrete market, low production quality can, first, become apparent in decades; second, it makes it difficult to determine an actual reason of structural damage.

Auctions as a model for tender arrangement are, first of all, acceptable not for all types of markets and, second, an auction is always initiated in a situation specified by information asymmetry: each party is well aware of its chances, but has a rough idea about competitors' potential. Third, estimation of total demand and supply values for each item, determination of a new price vector and communication with each individual require considerable costs. Market participants do not have any motivation to inform the centre (the auctioneer) about the proper item characteristics.

Wasteful expenditures such as investments into reputation have to be so considerable that an enterprise is unable to cover them by the current revenue within a small period of time [10]. This sign requires that a customer should be totally aware of investments into the reputation; moreover, it stipulates that a customer understands the information about investments into the reputation.

Low entry price. In this case a seller of highquality products prefers such a price strategy, which is unprofitable for sellers of low-quality products, provided long-term profit. In effect, sellers of any product quality gradation do not always have longterm business activity as a goal. Likewise, in case of a seller's reputation is lowered, he can enter the market under a new brand. 
Thus, in the context of asymmetric information distribution an increase in market functioning efficiency is inseparably linked with reorganization of the economic system government control, which is quite urgent under the economic crisis, when information connections between subjects are broken. Therefore, generation of sustainable connections between the trade market participants will favor high functioning efficiency.

All the given arguments indicate an urgent need for informational and economic mechanism development, which are to be targeted at reduction of information asymmetry negative consequences and intensification of competition interaction on a regional trade market.

\section{References}

1. Errowe C. Information and economic behavior. // Economic issues. 1995. № 5. P. 98-107.

2. Kuzminov Y. I. Institutional economics course: institutes, networks, transaction costs, contracts: textbook for high education students. / Y. I. Kuzminov, K. A. Bendukidze, M.M. Yudkevich. M.: State Establishment of High School of Economics Publishing, 2006. 442 p.
3. Rubin Y. B. Theory and practice of enterprising competition: Textbook / Moscow International Institute of Econometrics, Information Technology, Finances and Law. M., 2003. 584 p.

4. Lamben Z. Z. Strategic marketing. European Perspective. http://www.koob.ru/lamben_jan

5. Bokanov A. A. Information Aspects of Circulation // Current problems of modern economics: collection of scientific papers. Volgograd: Rigel Ltd., 2001. 192 p., p. 76-84

6. Kruglov V. V. Competition: learning aid. M.: "Velby" Trading company, Prospekt Publishing, 2004. 80 p.

7. Persky Y. K., Zhulanov E. E. Competition Environment of the Regional Trade Market: methods and models. Ekaterinburg: Institute of Economics of UB RAS, 2005. 307 p.

8. Kiyamov I. K. Construction sector in the Russian Economy. Kazan: Center for Innovation Technologies, 2001. $44 \mathrm{p}$.

9. Establishment of Construction Production: textbook for higher educational institutions. / T. N. Tsay, P. P. Grabovoy, V.A. Bolshakov and others. M.: ACB Publishing, 1999. 432 p.

10. Avdasheva S. B., Rozanova N. M. Theory of Trade Market Organization. Textbook. M.: Sole Proprietorship «Magistr Publishing», 1998. 320 p. 